Article

\title{
Challenges Faced by Maltese Students Studying Advanced Level Physics
}

\author{
Nathan Pullicino* and Charles Bonello \\ Department of Mathematics and Science Education, Faculty of Education, University of Malta, \\ Msida MSD2080, Malta; charles.bonello@um.edu.mt \\ * Correspondence: nathan.pullicino.14@um.edu.mt
}

Received: 7 July 2020; Accepted: 11 August 2020; Published: 17 August 2020

\begin{abstract}
One of the aims of the Secondary Education Certificate (SEC) Physics syllabus is "to provide the basis for further study of the subject". This research determined the extent to which the syllabus is fulfilling this aim. In this study, seven post-secondary Physics teachers participated in semi-structured interviews and 200 students provided feedback to a questionnaire. Areas in which the SEC Physics syllabus is not preparing students well enough to further their studies in the subject were identified and suggestions were given to help improve the situation. This study confirmed that there is an academic disparity between SEC and Advanced Matriculation (AM) Physics. This disparity is highlighted in the problem-solving skills necessary for success at both levels, mathematical physics, language and in concepts which are highly abstract. The study also confirmed that there is a large amount of rote learning involved in SEC level Physics. As a result, students learn superficially and struggle to grasp the complex concepts taught in A-level Physics. In order to prepare students better for post-secondary education, SEC Physics students should be asked to answer questions which involve higher levels of thinking and to solve more complex mathematical problems. Furthermore, more frequent practical sessions, a greater degree of student involvement and a greater emphasis on the link between theoretical ideas and practical work is also recommended. A shift of emphasis is required from teaching content to teaching higher order thinking skills.
\end{abstract}

Keywords: physics; syllabus; academic disparity; underprepared students

\section{Introduction}

At the end of compulsory schooling, students in Malta sit for the Secondary Education Certificate (SEC) examinations. These examinations test students on each of the subjects they studied between their 9th and 11th years of schooling. Students who obtain the necessary grades can then further their studies in their desired subjects at higher education institutions. After compulsory schooling, students can choose to study two Advanced level and three Intermediate level Matriculation subjects for two more years at post-secondary institutions. These institutions include what are known as sixth forms and pre-university colleges. The material at these levels would build upon that which was taught at SEC level. After studying these subjects for two years, students sit for the Advanced and Intermediate Matriculation examinations. The grades obtained in these examinations will determine whether or not students will gain access into university [1]. This study deals with the SEC Physics syllabus and the Advanced Matriculation (AM) Physics syllabus.

While in the past, Physics was the main science taught in schools, examiners' reports (2007-2018) indicate a decline in the number of students choosing to further their studies in the subject at post-secondary level. Many students enter post-secondary education underprepared for that level of work which they are expected to engage in. This results in low completion rates and underachievement $[2,3]$. Improving performance and preparedness at Secondary level could therefore 
encourage more students to further their studies in a particular subject [4]. Underprepared students lack the academic abilities which are necessary for success at the level of education in question due to prior educational experiences [5]. Societal factors, such as having a low socioeconomic background or focusing too much on grades rather than learning, may also increase the number of underprepared students [6].

In Malta, the SEC Physics syllabus aims "to contribute to the pupils' general education by helping them to make sense of the physical environment through scientific inquiry" and also "to provide the basis for further study of the subject" [7]. Therefore, the syllabus aims to both prepare students for further study in the subject and also provide other students with a degree of scientific literacy which is relevant to their everyday life.

One of the primary causes of underprepared students is the disparity between the level of skill required for success at secondary level and that required at higher levels [5]. If the skills needed to obtain a good mark for SEC Physics are too basic compared to those needed for AM Physics, then students looking to further their studies in the subject will be underprepared for higher education and will likely drop out. Furthermore, students who obtain good grades in certain subjects at SEC level tend to choose to further their studies those subjects at Advanced level [8]. Therefore, if the prerequisite material is too easy, or the disparity between the two levels is too large, students may be misled into choosing the subject at A-level.

On one hand, secondary level Physics education needs to be of a certain standard so that students will be prepared for further studies in the subject. On the other hand, students who do not choose to further their studies in the subject need to have a grounding in scientific literacy. This spectrum of needs must be addressed if the students' experience of learning SEC Physics is to be a fruitful one. Therefore, the material present at both SEC and AM Physics should be appropriately challenging for students

\section{Methodology}

Both quantitative and qualitative methods were used to conduct this study. Since the two main stakeholders involved in the teaching and learning of post-secondary Physics are AM Physics teachers and students, the views of both of these cohorts were taken into consideration in this study. This was decided in order to determine which factors, if any, contribute to having underprepared Physics students in post-secondary institutions.

In order to obtain feedback about AM Physics from past students, quantitative methods were used as opposed to qualitative ones, due to the large sample being considered. In this way, results could be generalized to the entire population of Maltese students. An online questionnaire was designed and completed by students who applied for the AM Physics examination between 2011 and 2018. Out of 3430 students who applied for the examination within this period, the questionnaire was completed by 200. This implies that using a 95\% confidence level, the statistical inferences of the questionnaire have a margin of error of $6.73 \%$.

The questionnaire was divided into four main parts. The first part of the questionnaire consisted of seven questions designed to provide information on demographics. The information obtained through this section included: gender, the type of school which students attended, the year in which they sat for their SEC and AM Physics exam, other academic subjects which students studied at advanced level apart from Physics, and the grades obtained in both SEC and AM Physics.

The second part of the questionnaire then consisted of seven more questions designed to obtain the general perception of students towards the SEC and AM Physics syllabi. These questions determined the overall level of difficulty of the material studied in both SEC and AM Physics according to students. Students were also asked to comment on the amount of content taught in both SEC and AM Physics as well as on the overall disparity between the two levels. Student opinions on the amount of Mathematics involved in SEC Physics were also obtained along with students' perceptions of what "direct proportionality" means. 
The SEC and AM Physics syllabi were compared to understand what students need to know at Advanced level and what grounding the SEC material provides. Recent SEC and AM Physics examiners' reports were then analyzed in order to identify common areas in which students struggle. These areas involved knowledge and skills which were supposed to be mastered at SEC level but were still lacking at A-level. For the third part of the questionnaire, students were asked six questions about how well they believe that the SEC Physics syllabus prepared them for parts of the AM examinations in which marks are commonly lost.

For the final part of the questionnaire, the AM Physics syllabus was split up into small sections. Students were given four questions in which to express their opinion on each individual part of the syllabus.

The views of post-secondary Physics teachers were also taken into consideration by means of qualitative methods in order to gain a more profound insight on the situation. Seven teachers from six different post-secondary institutions participated in semi-structured interviews and generated data about the challenges faced by Maltese students when studying AM Physics. The interviews consisted of two main parts. The introductory part consisted of five questions designed to acquire basic information about the teachers, such as the amount of experience teaching SEC and AM Physics.

The core part consisted of sixteen questions which gave teachers the opportunity to express their opinions on AM Physics and how well they feel that SEC Physics prepares students. Some of the questions were designed to confirm whether or not teachers agree with what students responded in the questionnaire. After conducting all seven interviews, their recordings were transcribed in order to be compared and contrasted. Content analysis was then performed by summarizing and categorizing the transcribed data.

\section{Results and Discussion}

\subsection{The Disparity between SEC and AM Physics}

Student grades confirmed that those students who obtain better grades at SEC level tend to perform better at AM Physics, as indicated in Figure 1.

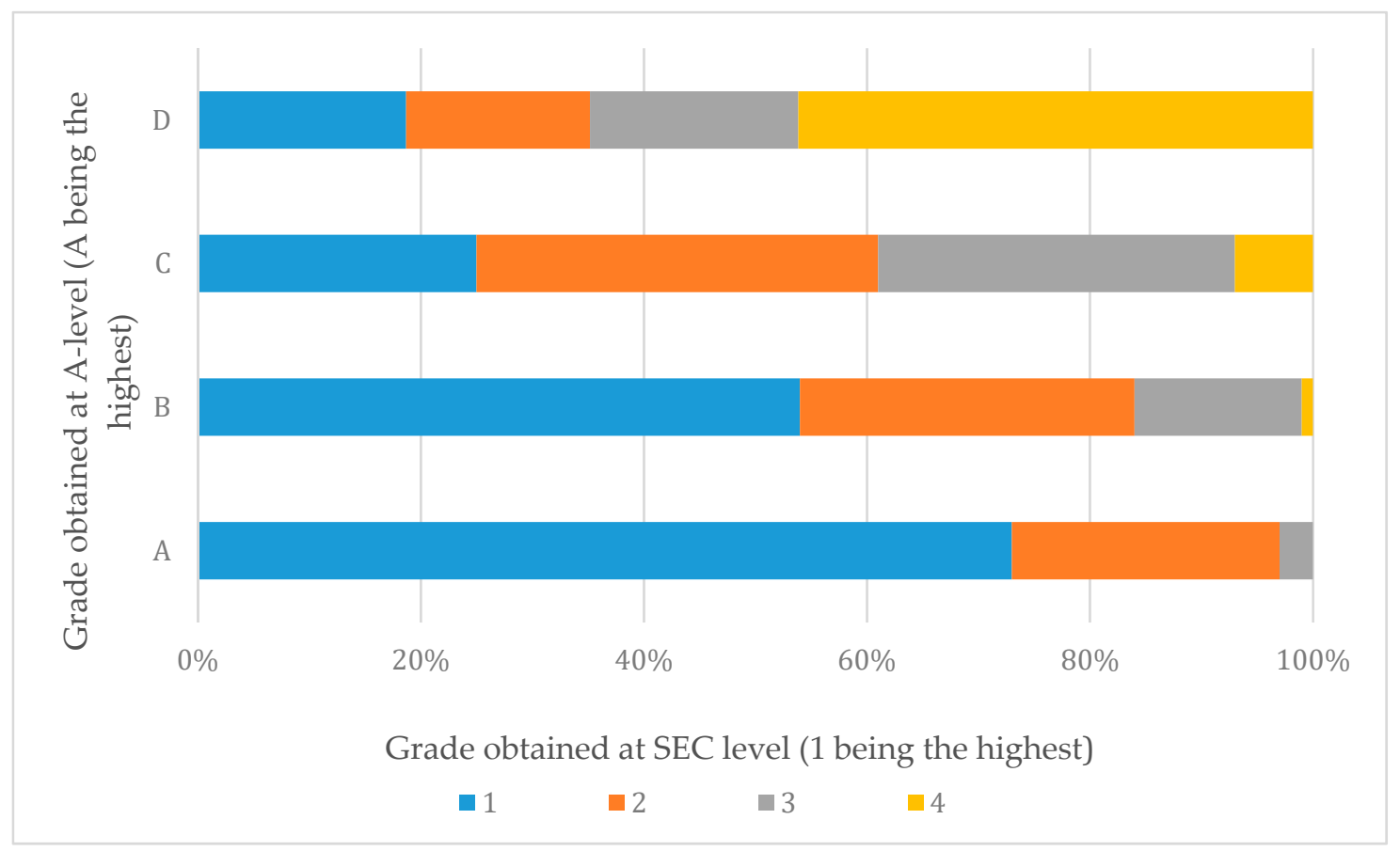

Figure 1. The grades obtained at Secondary Education Certificate (SEC) level and the corresponding grade at Advanced Matriculation (AM) level. 
Although the grade obtained at SEC level seems to be a good predictor of performance at AM Physics, it does not reveal much about how well prepared students are to further their studies in the subject. A disparity between the level of skill required for success at compulsory education and that required at higher education contributes to students being underprepared [6]. This study confirmed that most student participants found SEC Physics easy to understand and A-level Physics difficult as indicated in Table 1. Table 2 shows that the same cohort believe that there is a large disparity between the two levels.

Table 1. Student perceptions of the degree of difficulty of SEC and AM Physics.

\begin{tabular}{cccccc}
\hline $\begin{array}{c}\text { Difficulty on } \\
\text { Likert Scale }\end{array}$ & $\begin{array}{c}\text { Very Easy to } \\
\text { Understand }\end{array}$ & $\begin{array}{c}\text { Slightly Easy } \\
\text { to Understand }\end{array}$ & Adequate & $\begin{array}{c}\text { Slightly } \\
\text { Challenging }\end{array}$ & $\begin{array}{c}\text { Very } \\
\text { Challenging }\end{array}$ \\
\hline SEC Physics & $27.0 \%$ & $38.0 \%$ & $27.5 \%$ & $6.5 \%$ & $1.0 \%$ \\
A-level Physics & $2.5 \%$ & $8.0 \%$ & $19.0 \%$ & $54.5 \%$ & $16.0 \%$ \\
\hline
\end{tabular}

Table 2. Students on the disparity between SEC and AM Physics.

\begin{tabular}{cccccc}
\hline $\begin{array}{c}\text { The Gap between the Level of } \\
\text { Difficulty of SEC Physics and } \\
\text { that of A-Level Physics Was: }\end{array}$ & Very Small & Small & Adequate & Slightly Excessive & Excessive \\
\hline Percentage of respondents & $2 \%$ & $8 \%$ & $31 \%$ & $32 \%$ & $27 \%$ \\
\hline
\end{tabular}

Six out of seven interviewed teachers believe that the disparity between the two levels is too large. Three of these affirmed that SEC Physics is relatively easy to understand and mostly requires lower-order thinking skills. This results in students choosing to memorize concepts rather than understand and learn how to apply them. While rote learning may be beneficial and could help students to obtain better grades, an interviewed teacher stated that "we are doing a disservice to the better pupils" as we are not allowing those who can understand or want to learn the subject to truly do so. Another interviewed teacher stated that there is also quite a disparity from having problems at SEC level which only involve inputting values into an equation to having complex, multi-step problems at A-level.

\subsection{Mathematics and Problem-Solving}

Students at the secondary level lack problem-solving skills and thus struggle with mathematical calculations and higher order thinking skills [9]. Furthermore, it is difficult for students to succeed in Physics without a strong mathematical background [10]. If students are not being prepared well mathematically at SEC level, it will be harder for them to succeed at a level which is more mathematically demanding and requires the application of Mathematics to solve complex and unfamiliar problems [11]. All interviewed teachers agreed that while SEC Physics prepares students well to be able to recall and work out simple mathematical problems, it does not prepare them to think critically, apply what they know to unfamiliar situations, or solve complex, multi-step problems. One of these teachers elaborated that this may be due to:

- Students being too young to have sufficient problem-solving skills;

- Teachers avoiding problem-solving and opting to teach students to memorize;

- Exam questions asked encourage students to memorize and recall rather than think critically.

In response to this, teachers claimed that compulsory Physics needs to shift its focus from simply presenting content to teaching higher order thinking skills. This would mean that it is not just the syllabus which requires change, but also the teaching pedagogy. Furthermore, five out of the seven interviewed teachers agreed that students tend to be poorly prepared in Mathematics and struggle to understand the mathematical relationships found in AM Physics. These teachers elaborated that 
students especially struggle to comprehend aspects which should have been mastered at SEC level such as indices, algebra and simultaneous equations.

Two teachers noticed that the mathematical content of SEC Physics was being reduced. This was detrimental to students studying Physics as it gave them the impression that they do not need Mathematics to study Physics. Similarly, another two teachers mentioned that when there are problem-solving tasks, students coach themselves into working out enough examples to be able to recall the method used. This results in students having the false impression that they have good problem-solving skills. Two other teachers observed that students struggle to choose the right equation or deconstruct a problem in order to tackle it.

Another teacher suggested increasing the amount of Mathematics at SEC level so as to significantly challenge students in problem-solving and asking them to back qualitative answers mathematically in order for students to understand the links between Physics and Mathematics. Three teachers believe that exam questions asked in SEC Physics should push students to use algebra and solve challenging problems which involve multiple steps in order for students to be better prepared mathematically for further studies in the subject. These teachers remarked that this lack of experience in dealing with challenging mathematical situations leads to students struggling in topics which involve a greater deal of mathematical calculations such as 'Mechanics' and 'Electricity. In response to this, a teacher suggested splitting up the SEC Physics syllabus so that students who wish to further their studies in Physics can study higher levels of Mathematics at SEC level. These students would be challenged to solve complex problems in order to be well-prepared for A-level Physics.

On the other hand, $49.5 \%$ of students believe that they were well-prepared to be able to apply what they know to unfamiliar situations while only 30\% disagreed with this. In this study, most student participants believe that SEC Physics prepared them well mathematically when it comes to plotting graphs $(74 \%)$ and interpreting graphs $(68.5 \%)$, converting numerical values depending on the units being used $(88.5 \%)$ and relating graphical information to equations $(64.5 \%)$. That being said, $79.5 \%$ of student stated that the use of Mathematics should be better emphasized in SEC Physics. Results also indicate that $60.5 \%$ of student respondents were incorrectly taught that two variables are directly proportional if "one value increases as the other increases". In reality, this is an oversimplified explanation which gives an incorrect meaning to a fundamental relationship.

While challenging compulsory Physics students in Mathematics may lead to having better prepared students at A-level, two teachers expressed that students end up memorising content if Physics is taught through equations rather than concepts. One of these teachers elaborated that students immediately think of equations whenever 'Newton's Second Law' or 'Ohm's Law' are mentioned. Without any deeper thought, students think that these laws are about inputting values in order to obtain an answer.

Another teacher stated that students have misconceptions in graphs and gave the example that in velocity-time graphs, some students think that a straight horizontal line means that the object is at rest. This may also indicate that students memorize velocity-time and displacement-time graphs rather than understand what they represent, which results in mistaking one graph for the other. This further emphasizes the importance of using good pedagogies as while the Physics syllabus does well to ensure that students are familiar with both types of graphs, teachers must ensure that students are taught to reason out graphs.

Two teachers mentioned that some students learn how to change subject of the formula by remembering images such as Figure 2. This tool works in such a way that when students want to make Force subject of the formula, they cover ' $\mathrm{F}$ ' and remember that the equation would be equal to the pressure multiplied by the area. In this way, students are being trained to recall rather than understand algebra and the Physics behind the equation. While both teachers agree that tools such as this would be a good idea to use with low-achievers, it should not be used with everyone. Thus, once again, it is emphasized that teachers must ensure that their end-goal is to teach students to think and understand 
rather than memorize and recall. Furthermore, this triangle hinders future learning because students cannot apply it to harder equations.

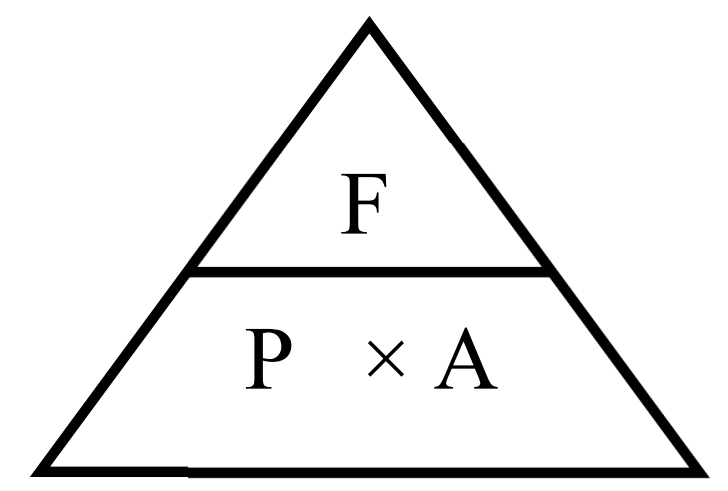

Figure 2. Tool to help students remember how to do subject of the formula for pressure in solids.

\subsection{Expression and Recall}

Most students find difficulties in expressing themselves in English and are concerned about the fact that they may not understand the question [12]. While the majority of student participants (78.5\%) agreed that they were able to use proper English to explain concepts, six out of seven interviewed teachers criticized that students are not being well prepared to understand the questions being asked and to express themselves in English.

A teacher attributed this difficulty of expression to what happens in the classroom as students are trained to only give the correct answer rather than being asked for their ideas and creating discussions. This teacher also noticed that when asked orally, students seem to be afraid to provide feedback. This may indicate a lack of confidence. Improving this situation therefore seems to be an issue related to pedagogy rather than content. According to the teachers, this divide between students' and teachers' opinions may be due to the fact that students are only trained to memorize and recall. It may therefore be that students are given the wrong impression of being well-prepared to describe concepts when in reality, they were well-prepared to recall theory.

One particular teacher mentioned that although there is still much to be done, the situation is improving. This improvement is perhaps due to the increase in the number of foreign students in schools which encourages Maltese students to make more use of the English language. This is further backed by the fact that the only teacher who did not mention that English is a problem teaches at an independent school. These schools normally have with a large number of foreign students.

\subsection{Pedagogies and Recall}

Pedagogies also effect the number of underprepared students [6]. Interviewed teachers noted that students from certain schools seem to be better prepared and have a more positive attitude towards learning.

Students confirmed that negative teaching styles, such as teaching for exam purposes, prevented them from fully understanding concepts at SEC level. Teachers argued that learning by memorizing has negative effects on student preparation and performance. Both stakeholders seem to think that SEC Physics should focus more on teaching students to think rather than recall. In this manner, one can ensure that concepts are well understood. What is assessed in examinations is key to be able to do this as two teachers claimed that since the SEC examinations rarely ask critical questions, teachers refrain from asking them in class and instead opt to train students for the exam. It therefore seems that the content present in the syllabus, what is asked in examinations and the teaching pedagogy are closely linked, as each factor can influence the other and has an effect on both student achievement and learning. 
According to another teacher, while memorizing could result in the students obtaining good marks in their SEC examinations, this is not possible at A-level, since there is too much to learn. Therefore, by teaching students to memorize, students are being given the wrong impression about how one should learn Physics. In their interview, two teachers also commented that students think that Physics involves a lot of recall and inputting values into equations.

\subsection{Proper Grounding}

Six interviewed teachers confirmed that when students have a good grounding at SEC level in a particular topic, students find new concepts related to the topic easier to grasp and are more participative and confident. Four of these teachers also observed that they cover material quicker and encounter fewer problems when there is good grounding. One of these teachers stated that in familiar topics, some students may be overconfident and are shocked once they see the level of detail which there is at A-level, especially compared to what is asked of the students at SEC level. Furthermore, even though students seem to understand the theory faster, they still struggle to apply it because the questions being asked at A-level which are related to these topics tend to be much harder. In response to this, a teacher believes that while familiarity makes students more comfortable and thus makes it easier for them to understand, it is important to get students out of their comfort zone so that they become used to applying what they know to unfamiliar situations.

In an open question on how to better prepare students for AM Physics, thirteen students suggested that compulsory Physics should cover the basic concepts of every area of Advanced level Physics, even 'Quantum Physics', in order to make learning less strenuous at post-secondary level. In relation to this, another teacher argued that when a topic is covered at SEC level, students are more likely to have misconceptions. In order to reduce the number of underprepared students, teachers in SEC education should therefore be aware of common misconceptions in order to be careful not to instil them in students and to tackle them should they arise.

Five interviewees believe that misconceptions hinder students from understanding and that it is harder for students to unlearn and adjust previously learned information than it is to learn something completely new. Students often recall information as it was taught to them at SEC level, even if this information is improved upon at A-level. For example, at SEC level, acceleration due to gravity is taken to be $10 \mathrm{~m} / \mathrm{s}^{2}$ while at A-level, it is taken to be $9.81 \mathrm{~m} / \mathrm{s}^{2}$. Students often continue to make use of the value used at SEC level even at A-level and end up losing marks as a result. In fact, the majority of respondents $(85 \%)$ agree that it would be beneficial to consider the acceleration due to gravity to be $9.81 \mathrm{~m} / \mathrm{s}^{2}$ at even compulsory level. Similarly, a teacher mentioned that since only the elastic limit is mentioned when covering Hooke's Law at SEC level, students often disregard the limit of proportionality at A-level and end up losing marks by stating that Hooke's law is obeyed up to the elastic limit.

Two teachers mentioned that A-level students struggle to comprehend vectors due to the lack of emphasis on the directional properties of vectors at SEC level which results in misconceptions. Three teachers commented that students also have significant misconceptions regarding what 'Voltage', 'Current', 'Heat' and 'Temperature' are. One of these teachers also mentioned that students have vague ideas about what 'Potential Energy' really is and that since only 'Gravitational Potential Energy' is thoroughly covered at the SEC level, students struggle to understand that there are other types of 'Potential Energy'. Therefore, SEC compulsory education should not teach specific ideas such as 'Gravitational Potential Energy' or 'Magnetic Fields' without first covering the general concepts, 'Potential Energy' and 'Fields', from which those ideas arise as it gives students the wrong impression.

Two teachers stated that misconceptions result from students memorizing and learning for exam purposes rather than properly understanding concepts. To tackle this issue, these teachers suggest moving away from a teaching-centered mentality to teaching Physics in the laboratory using experiments and discussing the results obtained. Another two teachers suggested using discussions and probing questions to ensure that concepts are properly understood by students rather than 
memorized. These comments indicate that misconceptions can be tackled both by tweaking the syllabi and also by using the right pedagogy.

One of these teachers elaborated that compulsory Physics should not be about content but rather about teaching students how to think and how to learn. In order to do so, the interviewee suggested getting students to design experiments and solve complex problems rather than recall. Another teacher stated that at the SEC level, students "skim through a lot of things but they don't go into any detail" as students know a number of concepts but do not know the reasoning behind them.

A teacher stated that students with a poor Chemistry background struggle to understand concepts such as 'Semiconductors' and 'Nuclear Physics'. Although time is an issue, teaching the basics of the atom in SEC Physics as learned though Chemistry would provide better grounding, even for concepts which are taught in SEC Physics such as 'Electrostatics'.

\subsection{Experimental Work}

The majority of students believe that they were well prepared by compulsory Physics to further their studies in all of the questioned areas related to practical work. On the other hand, only three interviewed teachers believe that students are being well prepared in this aspect. It was identified by both a number of additional student comments on the questionnaire and four interviewed teachers that students struggle to conduct electricity experiments on their own and work with circuits at post-secondary level. In an open question about how to improve experimental work in SEC Physics, around $20 \%$ of the questionnaire respondents mentioned that students should be given the opportunities to work independently. Both students and teachers confirm that at secondary level, students are given detailed instructions to follow, or are shown demonstrations rather than given proper time to think and the opportunity to conduct experiments on their own. Three teachers also mentioned that some students were not given the opportunity to set up their apparatus and circuits at SEC level, which then hindered their performance at A-level.

Two interviewed teachers elaborated that students are being brought up with a certain "rigidity" as they focus exclusively on getting the correct answer rather than learning. One of these teachers thinks that this is due to the fact that at SEC level, their grade reflects how well they perform in their practical work. This is backed by the fact that both teachers observed that students are used to being given step-by-step instructions to obtain higher scores in their laboratory reports. Therefore, it seems that focusing on getting better marks in their reports is hindering students from learning all the skills which can be learned through practical work.

A teacher suggested that SEC teachers should give hints rather than instructions so that students learn not to rely too much on their teachers. Another teacher voiced that students' ability to work on their own depends on their previous teacher. This conclusion came about due to the teacher noticing that students coming from certain secondary schools tended to be more comfortable at working on their own. Therefore, having a student-centered pedagogy which gives students the opportunity to discover for themselves helps minimize the number of underprepared students. In fact, three teachers suggested that an investigative approach to practical work, where the students plan the experiment, would be ideal so that the students learn how to properly conduct experimental work.

In an open question on how to improve Physics education, thirteen students commented that there needs to be a more evident link between practical and theoretical work. Furthermore, all interviewed teachers agree that SEC Physics does not prepare students well enough to properly relate precautions and errors. Five of them elaborated that students have a list of precautions and errors learned by heart but cannot relate precautions to their proper errors or apply them properly depending on the experiment.

In terms of calculations related to practical work, four teachers stated that students are able to calculate the gradient of a simple straight-line graph but struggle to arrange equations to straight line form and extract information by associating the gradient to the equation. Another teacher also 
commented that while students are able to perform the routine calculations which are memorized by heart, they do not understand what the gradient actually means.

\subsection{Difficult Areas of Advanced Level Physics}

Both student and teacher participants confirmed that students tend to find: 'Thermal Physics', 'Electric Currents', 'Electrostatic Fields', 'Magnetic Fields \& Electromagnetic Induction', 'Atomic, Nuclear \& Particle Physics' and 'Quantum Theory' difficult. Teachers also mentioned 'Waves' and 'Circular Motion' and elaborated that students tend to dislike or find these concepts difficult either because they are abstract or because they are not well-prepared for the level of mathematics involved. In fact, all interviewees mentioned that students struggle to understand abstract concepts and thus struggle to understand certain topics. On the other hand, all teachers agree that students are well-prepared for 'Optics' while six teachers believe that students are well-prepared for concepts related to 'Materials'.

Two teachers also attributed the fact that students tend to avoid answering exam questions related to 'Fields', 'Electromagnetism', 'Nuclear Physics' and 'Waves' to the abstract nature of the topics. Apart from being abstract, two teachers also mentioned that teaching Electrostatic and Magnetic Fields without first relaying what a field actually is results in misconceptions and hinders learning as students end up memorizing rather than understanding. Three teachers commented that having to imagine abstract concepts with limited knowledge can create misconceptions, and therefore, teachers need to use visuals and simulations and engage students in practical work in order to make concepts as concrete as possible. Using multiple representations such as graphs, tables, diagrams, equations, simulations and explanations may help students to better understand abstract concepts [13].

In 'Physical Quantities', five out of seven interviewees reported that students are able to recall units but don't understand the deeper meaning of derived units and are not well-prepared for the algebra required. In 'Mechanics', three teachers expressed that students are well-prepared from SEC level for 'Linear Motion' but struggle to understand 'Circular motion' due to there being no background at SEC level. Similarly, for 'Thermal Physics', two teachers reported that students are well-prepared for concepts related to 'Thermodynamics' but not well-prepared to learn 'Kinetic Theory', yet again a topic that includes many abstract ideas. Two teachers also stated that they would like 'Latent Heat' to be taught at SEC level while another teacher believes that these students should also cover the basics of 'Thermometry' to prevent students from forming misconceptions about 'Temperature'.

Two teachers believe that students should learn more about the atom at the SEC level in order to have some better grounding on which to build while another teacher commented that some basic Mathematics such as the 'decay equations' should be included at the SEC level.

\section{Conclusions}

Post-secondary Physics teachers were asked whether they would like SEC Physics to teach some of the easier concepts which are currently taught at A-level so that students can have a better background. Four interviewees would like SEC Physics to cover more material and go into more detail, but only if time permits this. The remaining three interviewees disagreed for the sole reason that compulsory Physics does not only cater for students who want to further their studies in the subject and therefore should only cover the main areas and ensure that they are well-covered. These teachers argue that since only around $11 \%$ of the students who sit for the SEC Physics examinations further their studies in the subject, covering more content would prove detrimental to the majority of students.

It seems as though SEC Physics teachers can better prepare students for post-secondary Physics courses by ensuring that during the SEC course students focus on higher order thinking skills, language, problem-solving and mathematics. At the same time, the syllabus content is conditioned by the fact that it must also take into consideration students who do not wish to further their studies in the subject and who simply need to get a pass in order to satisfy sixth-form entry requirements. Therefore, it may be time for the syllabus to be split up so that a more intense course caters to better prepare students for 
further studies while another one focuses on creating scientifically literate citizens. Furthermore, while the syllabus and its content dictates what students learn, the pedagogy also affects what students learn and the extent to which they learn it. Therefore, ensuring that students are well prepared for AM Physics also means ensuring that the syllabus content is presented in an effective manner.

Author Contributions: Both authors contributed to every aspect of this paper. Both authors have read and agreed to the published version of the manuscript.

Funding: This research received no external funding.

Conflicts of Interest: The authors declare no conflict of interest.

\section{References}

1. Sultana, R.G. The Secondary Education Certificate and Matriculation Examinations in Malta: A Case Study; Unesco International Bureau of Education: Geneva, Switzerland, 1999.

2. Balduf, M. Underachievement among College Students. J. Adv. Acad. 2009, 20, 274-294. [CrossRef]

3. Kamphoff, C.S.; Hutson, B.; Amundsen, S.; Atwood, J. A Motivational/Empowerment Model Applied to Students on Academic Probation. J. Coll. Stud. Retent. Res. Theory Pract. 2007, 8, 397-412. [CrossRef]

4. Gill, T.; Bell, J.F. What Factors Determine the Uptake of A-level Physics? Int. J. Sci. Educ. 2013, 35, 753-772. [CrossRef]

5. Heisserer, D.L.; Parette, P. Advising at Risk Students in College and University Settings. Coll. Stud. J. 2002, $36,69-83$.

6. Dzubak, C.M. What Skills and Whose Standards: Why Are Students Underprepared? Synergy. 2007. Available online: https://www.myatp.org/wp-content/uploads/2015/04/Synergy-Vol-1-Dzubak.pdf (accessed on 12 August 2020).

7. Matriculation and Secondary Education Certificate Examination Board (MATSEC) SEC Syllabus (2021): Physics. Available online: https://www.um.edu.mt/_data/assets/pdf_file/0006/355407/SEC24.pdf (accessed on 12 August 2020).

8. Caruana, C.; Muscat, M. Is SEC Physics an Adequate Preparation for Advanced Level? A Study of Teachers' and Students' Views. Available online: https://hydi.um.edu.mt/permalink/f/1b6nr0f/356MALT_ alma2117755510003956 (accessed on 12 August 2020).

9. Erinosho, S.Y. How Do Students Perceive the Difficulty of Physics in Secondary School? An Exploratory Study in Nigeria. Int. J. Cross-Discip. Subj. Educ. 2013, 3, 1510-1515. [CrossRef]

10. Bezzina, M. Attitudes to Physics. Available online: https://hydi.um.edu.mt/permalink/f/1b6nr0f/356MALT_ alma2120319570003956 (accessed on 12 August 2020).

11. Farrugia, J.; Ventura, F. Predictive validity of examinations at the Secondary Education Certificate (SEC) level. J. Malt. Educ. Res. 2007, 5, 21-44.

12. Pace, R. Students' Difficulties in Answering Quantitative and Qualitative Questions in SEC Physics. Available online: https://hydi.um.edu.mt/permalink/f/1b6nr0f/356MALT_alma2121749510003956 (accessed on 12 August 2020).

13. Heuvelen, A.V.; Zou, X. Multiple representations of work-energy processes. Am. J. Phys. 2001, 69, $184-194$. [CrossRef]

(C) 2020 by the authors. Licensee MDPI, Basel, Switzerland. This article is an open access article distributed under the terms and conditions of the Creative Commons Attribution (CC BY) license (http://creativecommons.org/licenses/by/4.0/). 